\title{
The Students' Activities and Their Responses in Mathematics Learning By Guided Worksheet
}

\author{
Baiduri \\ Department of Mathematics Education \\ Malang, Indonesia \\ baiduriumm@gmail.com
}

\begin{abstract}
This paper aimed at analyzing the use of guided worksheet in mathematics learning at Madrasyah Aliyah Muhammadiyah 1 Malang, especially in the students' activities and responses. This study was conducted by means of descriptive design with qualitative approach. The data were obtained through classroom observation and questionnaires distributed to the students in Grade X and XI of Social Science Stream, MA Muhammadiyah 1 Malang. The data were subsequently analyzed descriptively. The findings of this study have showed that the students were actively engaged in learning activities through peer discussion, reading, and questioning the concepts delivered by the teacher through the guided worksheet. Moreover, this study indicated the positive responses from the students in which they felt more motivated, eager to actively engage, and more triggered to think critically during the learning process.
\end{abstract}

Keywords-student's activities; student's responses; guided workshee; mathematics instructional activity.

\section{INTRODUCTION}

Pursuant to the Regulations of the Minister of Education and Culture Number 20 Year 2016 about the competency standards for primary and secondary school graduates, graduates of Madrasyah Aliyah (MA) have to fulfill three dimensional competences: affective, cognitive, and psychomotor. In order to achieve these competences, several subjects have been designed for Madrasyah Aliyah, one of which is mathematics. Further, the Regulations of the Minister of Education and Culture Number 21 Year 2016 about content standard states that competences for mathematics learning at secondary education level comprise:

a) Expressing the logical, critical, analytical, creative, meticulous, responsible, responsive, and persistent attitudes in solving problems

b) Possessing curiosity, confidence, continuous learning disposition, reflective thinking, and high interest in learning mathematics

c) Having a reliance on the use of mathematics and a critical thinking constructed from learning experiences

d) Having an open-minded and objective personality, as well as appreciation towards other's work during group interaction in daily activities.

e) Having the ability to communicate mathematics concepts clearly and effectively.
It is closed by Turner (2011) who said that mathemacial competencies were communication, mathematising, representation, reasoning and argument, strategic thinking, and using symbolic, formal and technical language and operations.

The achievement of those content standards (SI) is elaborated in core competences (KI) and bases competences (KD) that should be fulfilled by students after engaging in the instructional activities in defined level during particular period and thereby achieving the graduate competency standards (SKL) after completing the instructional objectives in certain education level. In order to achieve the expected $\mathrm{KI}, \mathrm{KD}$, and SKL, other varied standards such as: process standard and educator and educational field human resource standards are involved during the learning process. As an attempt to achieve those competences, mathematics in MA is allotted into 4 meeting hours per week for Mathematics and Science Stream (MIA) and into 3 meeting hours per week for Social Science (IIS) and Language Stream. To implement this, it requires well-planned mathematics instructional activities as well as mathematics teachers demonstrating professional competences.

The Regulations of the Minister of Education and Culture Number 22 Year 2016 about standard process regulates the planning of learning process that requires educators to develop lesson plans (RPP). There are many elements of lesson plans. Two of them are learning sources and learning activities. It indicates that instruction is a lengthy process and demanding activity of various components comprising students, teachers, learning materials, learning methods, and assessments (Kitao \& Kitao, 1997).

Learning source is defined as a learning aid used by teacher to assist students in achieving learning objectives, to increase students' access, to significantly contribute to students' progress, to facilitate learning process, and to be the key determinant to things happening during learning activities (Littlejohn, 2012). The learning source can comprise books, press and electronic media, surrounding nature or other relevant learning sources. Learning source or learning material is a salient aspect in the implementation of 
education at school. Through this learning source, teachers could easily develop learning process; and students, by which, could learn in an easy way. Learning source can vary depending on the offered learning needs and learning characteristics.

The learning process in this current study was designed and conducted on the basis of inquiry-based learning/investigation or problem-solving. It, moreover, has been stated that in terms of their profession, professional teachers are to possess professional competences in pedagogy, social aspects, and personality (the Regulations of Republic of Indonesia Number 14 Year 2005 Article 10 Section 1). The development of teacher professionalism has been globally concerned for teachers bear major roles and duties not only for providing scientific information/knowledge and technology but for developing or building students' characteristics as well, especially in this current hyper-competition era. Teachers' duty is mainly assisting students to be capable of adapting themselves in various daily-life problems. This sort of empowerment comprises personality aspects, especially intellectual, social, emotional, and skill aspects. That noble duty seems to be challenging and demanding not just because teachers should prepare younger generations to get into the science era, but also due to the sustainability of their existence either as individual or as professional. Mathematics teachers have crucial role in determining students' success (Even and Ball, 2009). What students do during learning process reflects the learning methods and strategies used by a teacher.

Related to the major duty at school, there are two main related competences that should be possessed and developed by teachers, namely: pedagogical and professional competences. The pedagogical competence is a typical characteristic distinguishing teachers from other professions. It basically entails teacher's ability in planning and managing learning process for students. It also compromises the ability in following up the current dynamical trends of knowledge. The professional competence reflects teacher's ability in rigorously mastering learning materials. These two competences must be upgraded in an attempt to follow up the current development of knowledge and technology. Döhrmann Kaiser, and Blömeke (2012) said that successful teaching depends on professional knowledge and teacher beliefs. The development of these competences can be done through the planning of learning materials and its implementation during learning process (the Regulations of the Minister of Education and Culture Number 22 Year 2016).

Based on the interview with mathematics teachers, the students of Madrasyah Aliyah Muhammadiyah 1 Malang (MAM I) were originating from Malang, other cities, and other regions. It indicated the heterogeneity in terms of social, economy, cultural, and educational backgrounds. The majority of the students were from low-level economy background. Further, it has been claimed that the learning sources in the school were very limited (many books could only be read in the library) and the students rather passively engaged during learning process, especially for those in Social Science Stream (IIS). The learning process was mainly utilizing learning source in form of student worksheet provided by the school. Teachers have not yet designed their authentic learning materials. The learning process, moreover, could not actively involve the students nor could it develop the students' learning motivation. Accordingly, teachers are expected to develop their authentic learning materials; and consequently, the learning process could fulfill the process standard.

One of learning material is a student worksheet (known as LKS). It is an effective tool used by teacher as an attempt to trigger students to activate their cognition during learning process in a classroom (Harries and Spooner, 2000). Student worksheet used in a class is also likely to facilitate students in direct learning outside class. According to Wyels, there are several advantages of student worksheet: 1 ) helping students to solely focus on basic principles of learning process, 2) bridging a gap in learning process, 3 ) maintaining students' focus in a class, 4) delivering and/or summarizing content, 5) triggering students to communicate their mathematics concepts, 6) helping students to learn from a textbook, and 7) connecting new materials to the preceding ones. Student worksheets used in this study were guided worksheets to help students to understand or discover mathematics concepts or mathematic properties. Based on student whorksheet advantages, analyzing the students' activities and responses about its used in the learning of mathematics was essential investigated.

\section{ObJective Of THE STUdy}

This study aimed to describe the students' activities and responses in mathematics learning through guided worksheet guided worksheet at Madrasyah Aliyah Muhammadiyah 1 Malang.

\section{Method Of StUdY}

\section{A. Subjects}

The students in Grade X and XI of Social Science Stream (IIS), MA Muhammadiyah 1 Malang were selected due the teacher's consideration from the interview results revealing that most of the students in these classes were very passive in learning process and lacked learning motivation. The first meeting in Class X IIS was attended by 15 students; while the second meeting was attended by 18 students. Meanwhile, in Class XI IIS the two meetings were attended by 25 students.

\section{B. Data Collection and Analysis}


The data were collected by means of observation during the learning process by two observers. After the learning process, the students were given semi-closed questionnaires related to (1) the learning activities before and during the use of guided worksheet and (2) the students' responses towards the learning implementation and selfreflection. The credibility of the data was obtained through the triangulation of source and technique, observation results from two observers, and questionnaire results. Eventually, the credible data were analyzed in narrative and descriptive by calculating the percentages of each student's activity in each meeting (Lambert and Lambert, 2012).

\section{Procedures}

The learning process in Grade X and XI of Social Science Stream was done by means of cooperative setting following the steps proposed by Meixia, et.al. (2007): 1) determining and explaining the learning objectives, 2) grouping the students, 3) explaining the assignment, 4) monitoring group discussion, and 5) assessing learning outcomes. These steps, in each meeting, were implemented into three integrated phases: pre-teaching, whilst-teaching, and post-teaching. In Class $\mathrm{X}$, the students were divided into three groups, each of which consisted of 5 to 6 students. Meanwhile, in Class XI, the students were divided into five groups consisting 5 students each. Jigsaw grouping was implemented in both classes (in Class X they counted to 3; while in Class $\mathrm{X}$ they counted to 5) without concerning on ability, gender, nor other characteristics.

The assignment were worksheet form of which activities referring to guided invention in understanding one or more concepts (guided whorksheet) were utilized in two meetings. This current study was conducted in odd semester of academic year 2016/2017. One meeting lasted for 2 x 40 minutes.

\section{RESUlTS AND Discussion}

The findings were elaborated based on the students' activities in each class of Grade X and XI for Social Science Stream (IIS). The students' activities were focused on core learning activity grouped into two: learning process before the use of guided worksheet and during the use of guided worksheet. Besides, the students were also required to respond to the learning activities and to perform selfreflection after the learning process.

\section{A. The Students' Activities}

\section{3}

Student's activity is a response tapped from what have been done by the teacher to the students. In whilst teaching, the teacher distributed guided worksheets while giving an assignment in the worksheet. While the students were working on their assignment, the teacher were monitoring the students' activity and assisting some groups with difficulties. In post-teaching, the teacher focused on the review of learning materials and summarized them altogether with the students.

\section{B. The students' activities before the use of guided worksheet}

Based on the results of observation and questionnaire, before completing the assignment in guided worksheet, the students completed several activities either as individual or group as a preparatory for completing the guided worksheet, such as: reading mathematics books beside the guided worksheet provided by the teacher, having a peer-discussion, and consulting to the teacher. The percentages of these activities are illustrated in Table 1.

TABLE 1. The StUdentS' Activities SOCIAL SCIENCE Stream

\begin{tabular}{|c|c|c|c|c|}
\hline \multirow{3}{*}{$\begin{array}{l}\text { Students' } \\
\text { Activity }\end{array}$} & \multicolumn{2}{|c|}{ Class X } & \multicolumn{2}{|c|}{ Class XI } \\
\hline & M I & M II & M I & M II \\
\hline & $\mathrm{N}=12$ & $\mathrm{~N}=18$ & $\begin{array}{c}\mathrm{N}= \\
20\end{array}$ & $\mathrm{~N}=22$ \\
\hline $\begin{array}{l}\text { Reading } \\
\text { Mathematics } \\
\text { Textbook } \\
\text { (beside } \\
\text { guided } \\
\text { worksheet) }\end{array}$ & $0 \%$ & $50 \%$ & $25 \%$ & $30 \%$ \\
\hline $\begin{array}{l}\text { Discussing } \\
\text { each other } \\
\text { related to the } \\
\text { learning } \\
\text { materials }\end{array}$ & $75 \%$ & $66.67 \%$ & $50 \%$ & $27.27 \%$ \\
\hline $\begin{array}{l}\text { Asking the } \\
\text { teacher about } \\
\text { the learning } \\
\text { materials }\end{array}$ & $50 \%$ & $50 \%$ & $15 \%$ & $18.18 \%$ \\
\hline
\end{tabular}

Note: M I: First meeting, M II: Second meeting

Based on Table 1, the activity performed by the students class $\mathrm{X}$ in pre-teaching process in the form of peerdiscussion decreased from $75 \%$ to $66.67 \%$. It was due to the activity of reading textbook (beside the guided worksheet provided by the teacher) which, in the first meeting, was not implemented yet. In the second meeting, this activity was done by $50 \%$ of the students. Meanwhile, the activity of asking the teacher related to the upcoming relevant learning 
materials was done in both first and second meetings. The others, in class XI there was an increase of reading and asking activities before the students completed the guided worksheet provided by the teacher. On contrary, the peer-discussion activity decreased during this process. The reading and peerdiscussion activities more dominant than asking the teacher activities.

\section{The Students' activities during the use of guided worksheet}

This activity relates to what the students did in groups to complete the provided guided worksheet. It also relates to the encountered problems while completing the guided worksheet. It is illustrated in Table 2.

TABLE 2. The Students' ACtivities Social SCIENCE STREAM DURING THE COMPLETION OF GUIDED WORKSHEET

\begin{tabular}{lccc|c}
\hline & \multicolumn{2}{c}{ Class X } & \multicolumn{2}{c}{ Class XI } \\
\cline { 2 - 5 } \multicolumn{1}{c}{ Students' Activity } & $\mathrm{M} \mathrm{I}$ & $\mathrm{M} \mathrm{II}$ & $\mathrm{M} \mathrm{I}$ & $\mathrm{M}$ II \\
& $\mathrm{N}=12$ & $\mathrm{~N}=18$ & $\mathrm{~N}=20$ & $\mathrm{~N}=22$ \\
\hline Reading and & $41.67 \%$ & $44.44 \%$ & $40.00 \%$ & $59.09 \%$ \\
understanding the & & & & \\
guided worksheet & & & & \\
$\begin{array}{l}\text { Discussing each other } \\
\text { Asking the teacher }\end{array}$ & $66.67 \%$ & $88.89 \%$ & $55.00 \%$ & $63.64 \%$ \\
\hline
\end{tabular}

From the Table 2, the students' activities in class X during the completion of the assignment increased, especially in reading, understanding the guided worksheet, and discussing each other. The increasing discussion by $22.22 \%$ affected the decreasing the students' activities in the form of asking the teacher, from $66.67 \%$ to $33.33 \%$. The others, there was an increase of activities in reading, understanding the guided worksheet, discussing each other, and asking the teacher in class XI. The dominant activities done by the students were reading and peer-discussion while finishing the guided worksheet.

The students in class $\mathrm{X}$, during the learning process in the first meeting, there were $91.67 \%$ of the students who got difficulties in understanding the materials; and $58.33 \%$ of whom got difficulties in completing the assignment. In the second meeting, the percentage of both students' difficulties in understanding the learning materials and completing the assignment decreased as much as $66.67 \%$ and $27.78 \%$ respectively. The activity of asking the teacher increased by $88.89 \%$; while peer-discussion increased by $66.67 \%$.

Meanwhile during the learning process in the class XI, there were $40 \%$ (in the first meeting) and $31.82 \%$ (in the second meeting) of the students who got difficulties in understanding the materials. The difficulties in completing the assignment in the first and second meeting were $50 \%$ and $40.91 \%$ respectively. The communication difficulties were $30 \%$ in the first meeting and $22.73 \%$ in second one. The difficulties in asking the teacher were $20 \%$ and $18.18 \%$ respectively. It indicated that there was a decrease of the students' difficulties during both first and second meetings. To solve these, $50 \%$ of the students in the first meeting and $72.73 \%$ in the second meeting asked the teacher; $45 \%$ of the students in the first meeting and $40.91 \%$ of the students in second meeting discussed each other; and $20 \%$ of the students in the first meeting and $31.82 \%$ of the students in the second meeting reviewed the learning materials.

These findings showed that the students in Class $\mathrm{X}$ and XI IIS before and during completing the guided worksheet strived to understand the assignment by reading other textbooks, seriously understanding the learning materials, and actively engaging in the learning process. It reflected the learning objectives of mathematics learning, which are responsible and persistent in solving problems (the Regulations of the Minister of Education and Culture Number 21 Year 2016; Harries and Spooner, 2000). Others, the guided worksheet made the student focus on learning process and triggering students to communicate their mathematics concepts (Wyels; Harries and Spooner, 2000).

While facing difficulties during the learning process, the students reviewed the materials, discussed each other, and asked the teacher. These activities reflected the nature of mathematics learning, which is persistent, having great curiosity, open-minded, and continuous learning motivation. It indicated that the guided worksheet given by the teacher has significantly contributed to the students' progress, facilitated them during learning process, and affected the learning activities in the class (Collopy, 2003; Remillard, 2005; Lloyd, 2008; Littlejohn, 2012). In terms of sociocultural perspective in mathematics learning, the guided worksheet developed by the teachers has fulfilled the learning background, mathematics concepts, and the students' needs (Forman, 2003).

\section{The Students' Responses and Reflections}

Students“ responses including learning motivation, active learning, thinking, and joyful feeling. In the class X, the students' responses towards learning process increased in terms of learning motivation from $50 \%$ to $77.22 \%$, active engagement from $58.33 \%$ to $77.78 \%$, and thinking stimuli from $42.67 \%$ to $44.44 \%$. Meanwhile, the students' joyful feeling of learning decreased from $50 \%$ to $38.89 \%$.

In post-teaching process, the students expressed that they had understood the learning materials by $75 \%$ in the first meeting and $77.78 \%$ in the second meeting. There were $58.33 \%$ and $11.11 \%$ of the students in both first and second meetings understanding the learning materials that had not yet previously understood. There were $83.33 \%$ of the students in the first meeting and $55.56 \%$ in the second meeting who confessed that they had learned seriously. It was supported by the results of the assignment in the guided worksheet. All groups could thoroughly complete the assignment and understand the concepts of absolute-value inequality.

Furthermore, the students' responses in the class XI towards the learning model decreased: being motivated (from $85 \%$ in the first meeting to $63.64 \%$ in the second meeting), active engagement (from $55 \%$ in the first meeting to $54.55 \%$ in the second meeting), feeling pleasant (from $45 \%$ in the first meeting to $31.82 \%$ in the second meeting), and thinking stimuli (from $40 \%$ in the first meeting to $27.27 \%$ in the second meeting). After the learning process, the students 
confessed that their understanding upon the learning materials decreased from $75 \%$ in the first meeting to $50 \%$ in the second meeting. Their learning motivation also decreased from $75 \%$ in the first meeting to $45.45 \%$ in the second meeting. Besides, they also realized the decrease of incomprehensible materials from $60 \%$ in the first meeting to $22.73 \%$ in the second meeting. It was affirmed by the assignment results. In the first meeting, all groups could thoroughly complete the assignment in understanding the concept of matrix operation and its properties. In the second meeting, however, they had difficulties in understanding the concept.

After the learning process, the students stated they were aware of the subject matter that is already controlled and not well understood, and claimed have been studied in earnest. This indicates that the students conducted an reflection of the activities carried out during the learning process or metacognition (Parson et al, 2001; Desoete et al, 2001). Further, guided worksheet keep students motivated, engaged, stimulate thinking process and enjoy in the learning process.

\section{CONCLUSION}

The results of the study showed that the students in Class X and XI of Social Science Stream (IIS) have learned seriously, been actively engaging during the learning process, and been motivated to learn through the use of the guided worksheet. Despite these, the students remained dependable towards others, either friends or teacher, in solving the learning difficulties. The most salient aspect that should primarily be concerned for the teachers is that there were still a high number of students who got communication difficulties both with their friends or teacher. As a result, the teachers should necessarily be trained and guided continuously in developing the learning materials, especially for guided worksheet or other learning source and how to greatly implement them in learning processes. This study analyzed both students' activities and responses towards the use of guided worksheet. Therefore, it is still critical to conduct further study related to other aspects such as students' thinking process in completing the guided worksheet.

\section{REFERENCES}

[1] Anonymous, the Regulations Number 14 about Teachers and Lecturers, 2005.
[2] the Regulations of the Minister of Education and Culture about the Competency Standards for Primary and Secondary Graduates, 2016.

[3] the Regulations of the Minister of Education and Culture, the Republic of Indonesia Number 21 about the Content Standard for Primary and Secondary Educations, 2016.

[4] the Regulations of the Minister of Education and Culture, the Republic of Indonesia Number 22 about the Standard Process for Primary and Secondary Educations, 2016.

[5] R. Collopy, "Curriculum materials as a professional development tool: How a mathematics textbook affected two teachers' learning," Elementary school journal, pp. 103, 287-311, 2003.

[6] A. Desoete and H. Roeyers, and A. Buysse, "Metacognition and mathematics problem solving in Grade 3," Journal of learning Disabilities, pp. 34, 435-449, 2001.

[7] M. Döhrmann and G. kaiser, and Blomeke S., the conceptualisation of mathematics competencies in the international teacher education study TEDS-M, ZDM, 44(3), 2012, pp. 325-340.

[8] Even R: Ball, D.L., setting the stage for the ICMI study on the professional education and development of teachers of mathematics, new york: springer: the professional education and development of teachers of mathematics, 2009.

[9] E. A. Forman, A socio-cultural approach to mathematics reform: speaking, inscribing, and doing mathematics within communities of practies. In J.Kilpatrick, W.G. Martin, \& D. Schifter (Eds), Reston, VA: National Council of Teachers of Matehmatics: A research companion to principles and standards for school mathematics (pp. 523), 2003.

[10] T. Harries and M. Spooner, Mental mathematics for the numeracy hour, London: David Fulton, 2000.

[11] K. Kitao and S.K. Kitao, "selecting and developing teaching/ learning materials.," 1997. [Online]. Available: http://iteslj.org/Articles/KitaoMaterials.html.

[12] Lambert, V.A. and Lambert, C.., Qualitative Descriptive Research: An Acceptable Design. Pacific Rim Int J Nurs Res, 16(4), 2012, pp. 255-256.

[13] A. Littlejohn, Language teaching materials and teh (very) big picture. Electronic Journal of Foreign Language teaching, 9(1), 2012, pp. 283297.

[14] G. Lloyd, Teaching mathematics with a new curriculum: changes to classroom organization and interactions. Mathematical Thingking and Learning, 10, 2008, pp. 163-195.

[15] Ding Meixia, Li Xiaobao, Piccola Diana, and Kulm Gerald, "Teacher invervention in Cooperative-Learning Mathematics Classes," The journal of Education Research, no. 100(3), p. 162, 2007. 
[16] Ricard D Parsons \& Steoanie Lewis Hinson, Deborah Sardo-Brown, Educational psychology: A Practitioner Research Model of Teaching, Wadsworth: Thomsom Research, 2001.

[17] J. Remillard, "Examining key concepts in research on teachers' use of mathematics curricula," Review of Educational research, no. 75, pp. 211-246, 2005.

[18] R. Turner, "Exploring mathematical competencies.," Research Developments, no. 24(5), pp. 1-6, 2011.

[19] C. Wyels, "Engaging Students via In-Class Worksheets," [Online]. Available: $\quad \mathrm{http} / / / \mathrm{www}$.maa.org/programs/faculty-anddepartments/curriculum-department-guidelines-

recommendations/innovative-teaching-exchange/in-class-worksheets 